\title{
A prospective controlled investigation of the cognitive effects of amateur boxing
}

\author{
Richard J Butler, W Ian Forsythe, David W Beverly, Laurence M Adams
}

\begin{abstract}
Eighty six amateur boxers underwent a series of neuropsychological assessments on three occasions-pre bout, immediate post bout and follow up within two years; 31 water polo players and 47 rugby union players acted as controls. The neuropsychological tests were selected as being sensitive to subtle cognitive dysfunction and formed part of a battery of other neurological and ophthalmic assessments. No evidence of neuropsychological dysfunction due to boxing was found, either following a bout or a series of bouts at follow up. None of a range of parameters including number of previous contests, recovery from an earlier bout, number of head blows received during a bout and number of bouts between initial assessment and follow up, were found to be related to changes in cognitive functioning.
\end{abstract}

(F Neurol Neurosurg Psychiatry 1993;56:1055-1061)

Boxing evokes extreme and contrasting moral opinions. Proponents take the stance that boxing at an individual level encourages the development of self esteem, fitness and self discipline $^{1}$ and societies which condone the sport acknowledge the individual's freedom of choice. ${ }^{2}$ On the other hand, opponents view it as indefensible on the grounds that the predetermined aim is to cause physical damage to another competitor, ${ }^{3}$ that it encourages exploitation and corruption amongst the organisers of the sport, ${ }^{4}$ and that it degrades and fosters violent behaviour amongst boxers and observers. ${ }^{5}$ The debate over abolition or reforms to improve safety have been widely taken up. ${ }^{5-9}$

Never far from the discussion has been the medical assessment and evaluation of the relationship between boxing and injury. ${ }^{10}$ The discussion, however, usually centres on evidence for neurological or neuropsychological dysfunction. ${ }^{11}$

The most common and insidious injurious effect of boxing has been described as chronic brain damage, ${ }^{12}$ which might range from mild subclinical dysfunction detected only through neuropsychological investigation, to the slowed motor performance, tremors, memory defect, slowness of thought and personality change seen in the "punch drunk syndrome"..$^{13}$

It has been argued that improved medical supervision, reduced number of bouts and the improved safety regulations of the modern era have reduced the incidence of severe injury. In 1984, however, the British Medical Association passed a resolution supporting the abolishment of boxing and stated "that in view of the proven ocular and brain damage resulting from professional boxing, the association should campaign for its abolition". ${ }^{14} \mathrm{By}$ 1986 American, Australian, and Canadian medical organisations had taken a similar line. Professional boxing has further been made illegal in countries such as Sweden, Norway and Czechoslovakia.

There are relatively few studies of neurological and neuropsychological functioning in boxers which meet adequate design specifications. Most reports are anecdotal or survey groups of boxers with suspected neurological dysfunction. ${ }^{3}$ The majority lack a control group for comparison, fail to make a distinction between amateur and professional boxers and take retrospective account of former participants. Jordan ${ }^{15}$ has stressed the need to be mindful of inappropriate conclusions which result from poorly designed studies supporting a subjective and popular opinion and propagated through the medical literature as fact.

With professional boxing, early investigations of former contestants suggested a high incidence of neurological dysfunction particularly in the cerebellar and extra pyramidal areas, ${ }^{16-18}$ and at post mortem neuropathological abnormality of the septum pellucidum has been found in $92 \%$ of former professional boxers. ${ }^{19}$ Later studies incorporating CT and EEG have shown abnormalities in up to $50 \%$ of professional boxers. ${ }^{20} 21$

Studies of amateur boxers have in general, drawn different conclusions. British, American, Danish and Swedish studies all report no CT, EEG, auditory evoked potential or neurological abnormality in current and former amateur boxers. ${ }^{22-27}$ Thus there appears strong supporting evidence from across a variety of neurological assessments for the notion that amateur boxing does not result in observable morphological changes.

Neuropsychological assessment has been advocated as the most sensitive instrument for detecting subtle neurological abnormality. ${ }^{122324}$ Table 1 shows twelve studies which have incorporated neuropsychological tests of functioning into the assessment procedure.

Neuropsychological assessments undertaken with professional boxers have indicated 
Table 1 Studies reporting neuropsychological investigation of boxers

\begin{tabular}{|c|c|c|c|c|c|}
\hline Study & Number & Am/Pro & $\begin{array}{l}\text { Activel } \\
\text { former } \\
\text { boxer }\end{array}$ & $\begin{array}{l}\text { Control } \\
\text { group of } \\
\text { sportsmen }\end{array}$ & Comments \\
\hline $\begin{array}{c}\text { Roberts }^{17} \\
1969\end{array}$ & 178 & Pro & Former & - & $\begin{array}{l}\text { Low vocab score reflecting } \\
\text { educational background }\end{array}$ \\
\hline $\begin{array}{l}\text { Thomassen } \\
\text { et al } 1979\end{array}$ & 53 & Am & Former & Soccer & No difference \\
\hline $\begin{array}{l}\text { Kaste } e t a l^{21} \\
\quad 1982\end{array}$ & 14 & $\begin{array}{l}6 \text { Pro } \\
8 \mathrm{Am}\end{array}$ & $\begin{array}{l}13 \text { former } \\
1 \text { active }\end{array}$ & - & $\begin{array}{l}\text { No abnormality with } \\
\text { amateurs; } 2 \text { professionals } \\
\text { showed abnormal scores }\end{array}$ \\
\hline $\begin{array}{l}\text { Sironi et al } \\
\quad 1982\end{array}$ & 10 & Pro & Active & - & Normal \\
\hline $\begin{array}{l}\text { Ross et al }{ }^{20} \\
\quad 1983\end{array}$ & 40 & $\begin{array}{l}27 \text { Pro } \\
13 \mathrm{Am}\end{array}$ & & - & $\begin{array}{l}\text { Professional boxers scored } \\
\text { abnormally on test of } \\
\text { memory }\end{array}$ \\
\hline $\begin{array}{l}\text { Casson et al } \\
\quad 1984\end{array}$ & 18 & $\begin{array}{r}13 \text { Pro } \\
5 \mathrm{Am}\end{array}$ & $\begin{array}{l}13 \text { former } \\
5 \text { active }\end{array}$ & - & $\begin{array}{l}\text { Abnormal scores correlated } \\
\text { with number of pro. bouts- } \\
\text { Amateurs all normal scores }\end{array}$ \\
\hline $\begin{array}{l}\text { Drew et } a l^{28} \\
\quad 1986\end{array}$ & 19 & Pro & Active & $\begin{array}{l}\text { Basketball } \\
\text { and } \\
\text { baseball }\end{array}$ & $\begin{array}{l}\text { Boxers performed worse } \\
\text { than controls } \\
\text { High correlates between } \\
\text { number of bouts and } \\
\text { abnormal scores }\end{array}$ \\
\hline $\begin{array}{l}\text { Brooks et al } \\
\quad 1987\end{array}$ & 29 & Am & Active & $\begin{array}{l}\text { Am boxers } \\
\text { in training } \\
\text { but not } \\
\text { sparring }\end{array}$ & $\begin{array}{l}\text { No evidence that amateur } \\
\text { boxing causes neuropsych. } \\
\text { abnormalities }\end{array}$ \\
\hline $\begin{array}{l}\text { Levin et al }{ }^{33} \\
\quad 1987\end{array}$ & 13 & $\begin{array}{l}11 \text { Pro } \\
2 \mathrm{Am}\end{array}$ & Active & $\begin{array}{l}\text { Amateur } \\
\text { athletes }\end{array}$ & $\begin{array}{l}\text { No difference between } \\
\text { boxers and control. } \\
\text { Both improved on } \\
\text { follow up }\end{array}$ \\
\hline $\begin{array}{l}\text { McLatchie et } a l^{24} \\
1987\end{array}$ & 20 & Am & Active & & $\begin{array}{l}\text { Large variance with small } \\
\text { sub group (not always the } \\
\text { same subgroup) performed } \\
\text { badly on each test }\end{array}$ \\
\hline $\begin{array}{l}\text { Heilbronner } \\
\text { et } a l^{34} 1991\end{array}$ & 23 & Am & Active & - & $\begin{array}{l}\text { Over one bout, deficits in } \\
\text { verbal learning but } \\
\text { improvement in motor } \\
\text { speed }\end{array}$ \\
\hline $\begin{array}{l}\text { Murelius and } \\
\text { Haglund } \\
1991\end{array}$ & 50 & Am & Former & $\begin{array}{l}\text { Soccer, } \\
\text { track and } \\
\text { field }\end{array}$ & $\begin{array}{l}\text { No difference other than } \\
\text { finger tapping }\end{array}$ \\
\hline
\end{tabular}

some dysfunction particularly with memory. ${ }^{20} 21$ There also appears to be a relationship between the incidence of abnormality and length of career, ${ }^{23}$ number of bouts, ${ }^{12} 2328$ number of knock outs ${ }^{29}$ and with heavier weight categories. ${ }^{17}$ Such links conform with the model of cumulative effect in which it is proposed that blows to the head have an additive deleterious effect. ${ }^{30}$

With amateur boxers the picture again appears different. McLatchie et $a l^{24}$ detected some neurological and psychoneurological dysfunction in active amateur boxers, but when the same researchers compared the boxers with a control group, they failed to demonstrate any difference in neuropsychological functioning. ${ }^{31}$ In comparison with other sports no difference in neuropsychological functioning has been found between former amateur boxers and soccer players, ${ }^{22}$ a result later confirmed in a comparison of former amateur boxers with soccer players and track and field athletes. ${ }^{32}$

On a range of neuropsychological tests and other measures of cognitive functioning, which assess abilities such as motor speed, memory, verbal comprehension and visuospatial functioning, former amateur boxers have performed within normal limits. ${ }^{22}$ Mureluis and Haglund ${ }^{32}$ compared former amateur boxers with a long career (25-180 bouts) with those of a short career (0-15 bouts) and again no differences in neuropsychological functioning emerged, suggesting that the model of cumulative effect appears not to operate in amateur boxing.

The need to differentiate amateur boxing from professional boxing because of shorter duration of bouts and strict medical supervision of the former has been stressed. ${ }^{10}$ Stiller and Weinberger ${ }^{11}$ have further recommended the need for controlled prospective studies to evaluate the neuropsychological effects of boxing, and as table 1 shows, most studies so far have assessed boxers not currently active in the sport and only three studies ${ }^{22}{ }^{23} 32$ have used a control group. Only one study has attempted to assess boxers longitudinally, over a six month period, and they found no evidence for deterioration amongst a range of psychometric investigations. ${ }^{33}$ However, the group of boxers was comprised of a mixture of professional and amateur boxers, only two of which were actively boxing at an amateur level. A recent attempt to assess cognitive change after a bout of amateur boxing found some minor deficits in verbal learning, yet improvements in motor speed, when examined 30-45 minutes after boxing. ${ }^{34}$ The authors concluded, however, that it was difficult to determine whether brain dysfunction had occurred because of a lack of control group and because the number of head blows during the contest had not been calculated. The present study reports on a controlled prospective investigation of a large group of active amateur boxers. Boxers were compared with athletes from the sports of rugby union, a body contact sport, and water polo, a noncontact sport. They underwent an assessment of neuropsychological functioning before competition and were followed up with reassessment following competition and again some months later.

The neuropsychological assessments were part of a large battery of assessments including neurology, EEG, CT scan, brainstem evoked response, CKBB enzyme study and ophthamological assessment the results of which are reported elsewhere. The design sought to compare amateur boxing with controls from other sports, with particular emphasis on examining the effects of one bout, and longitudinally over an extended period of competition.

\section{Method}

SUBJECTS

Eighty six amateur boxers with a mean (SD) age of $16.7(2 \cdot 80)$ years and ranging in age from 12.6 to $26 \cdot 1$ years were recruited from local amateur boxing clubs after a visit from a member of the research team who described the purpose of the study. On inclusion no boxer had neurological impairment and all were active in training.

A total of 42 of the 86 boxers had not boxed in the preceeding 28 days, and 11 had not had a contest before the first examination. Mean length of competitive career was 2.09 years (range $0-9.5$ years), with a mean number of contests at 16.6 (range $0-75$ ). The number of winning contests ranged from 0-65, and losing stoppages $0-4$. Forty two had no losing stoppages and $72(94 \%)$ had no history of a knock out. 
Forty seven rugby union players with a mean (SD) age of $16 \cdot 8(2 \cdot 80)$ years and age range from 13 to 27 years and 31 water polo players with a mean (SD) age of $17.3(2.54)$ years and age range from 14 to 26 years were recruited as controls.

Exclusion criteria for all sports were known exposure to organic solvents, previous head injury, heavy drinking and any other known reason that might cause brain dysfunction.

\section{MEASURES}

Evidence from studies with professional boxers suggested the two most vulnerable areas of cognitive functioning were short term memory deficits ${ }^{23}$ and speed of performance. ${ }^{21}$

Thus tests were selected to measure these two functions. Note was also taken of tests shown to be sensitive to the effects of brain injury, ${ }^{35}$ standardised on an age equivalent population, concise and readily portable. Four of the tests (those marked ${ }^{\star}$ were taken from the British Ability Scales, a standardised assessment of intellectual performance. Tests in order of administration were:

\section{IMMEDIATE VISUAL RECALL (IVR)*}

This task is designed to measure immediate visual memory. A card of 20 pictures of common objects was presented for two minutes. The pictures were named by the investigator. The card was then removed and the athlete asked to recall the pictures, the score being the number correctly recalled.

\section{VISUAL SCANNING (VS)}

As a measure of inattentiveness, ${ }^{36}$ this test involves the scanning of an A4 size page of random letters. The task was to mark all the letter G's whilst being timed. The frequency of letter G's was twice that of any other letter. The score was the time per item correctly marked.

3 IMMEDIATE WORD RECALL (IWR)

Twenty single high frequency words four to six letters long were presented on a card for two minutes, and the athlete encouraged to remember as many as possible. ${ }^{37}$ The card was removed and the athlete asked to recall the words. The score was the number correctly recalled.

4 SPEED OF INFORMATION PROCESSING (SIP) * This consists of a booklet of 10 pages of random numbers. On each page there are 5 lines of 5 numbers (the digit length ranging from 4-5). The task was to mark off the highest number on each line whilst being timed on each page. It is argued this test is one of 'power' and is responded to irrespective of the person's level of intellectual ability. ${ }^{38}$ The test was scored according to the BAS criteria, which ascribes an ability score depending upon speed of completion.

5 RECALL OF DESIGN (RD) *

This is a visuomotor retention test, similar in administration to those used in other neu- ropsychological studies of boxers. ${ }^{212333}$ It required the athlete to observe a series of line drawings for 5 seconds and then attempt to draw the design from memory. It is scored according to the BAS criteria, with a score of 2 for a near perfect representation, a score of 1 for a partially correct drawing, and 0 for a drawing which is incorrect in one or more major aspects. A total score is the summation of scores for each design.

6 SERIAL ADDITION (SA)

This is an adaptation of the Paired Auditory Serial Addition Test and measures rate of information processing. It has been found to be sensitive to the effects of concussion. ${ }^{39}$ The athlete was presented with a sequence of single digits, the task being to add the second digit to the first, the third to the second and so on in sequence, whilst being timed to complete the sequence. The test was scored in terms of time to complete the task.

7 DELAYED VISUAL RECALL (DVR) *

Some 20 minutes following the IVR test the athlete was asked to recall the pictures on the original card. The score was the number correctly recalled.

\section{DELAYED WORD RECALL (DWR)}

Similarly the athelete was asked to recall words from the IWR test, 20 minutes after the initial presentation, and all the words correctly recalled comprised the score.

\section{VISUAL RECOGNITION (VR)}

To test the recognition aspect of memory the original 20 pictures from the IVR test were presented randomly amongst 60 distracter pictures. The distracter pictures consisted of 20 pictures often associated with the target picture (for example, chair-table), 20 pictures of objects of the same classification (for example, wine bottle-milk bottle), and 20 pictures of items from the Word Recall Test. The task was to select the original target pictures. Two scores were obtained-those correctly identified (recognition) and those pictures selected in error (error).

10 WORD RECOGNITION (WR)

A card of 80 words including the 20 words from the IWR tests was presented. The distracter words included 20 words of objects from the Visual Recall Test, 10 semantically similar words (such as, ship-boat), 10 visually similar words (such as, belt-bolt) and 20 words connected with sport (such as, pass, kick, skill, tactical). The task was again to identify the original target words from the IWR test. Two scores were again derivedthe number of words correctly identified (recognition) and the number incorrectly selected (errors).

\section{PROCEDURE}

A detailed history of the subject's involvement in the particular sport was taken. This included details of most recent competitions, and in the case of the boxers, a recent spar- 
ring history. Before competition, the subjects underwent a series of investigations at the local general hospital. These included, in order of administration: a neurological test, tests of cognitive functioning, brainstem evoked response, EEG, CKBB isoenzymes and ophthalmological assessment. The complete administration took one to one and a half hours. For boxers, the bout following the initial assessment was videotaped and subsequently analysed by an experienced boxing judge, assessing the number of moderate and severe head blows received.

As soon as possible following competition each subject repeated the series of investigations at the hospital. A total of $67 \%$ of boxers were assessed within 24 hours of the bout. The range was 1 to 6 days. At this juncture each subject had a CT scan. The investigations were again repeated at follow up which in some cases was nearly two years since the initial assessment. Detailed notes were taken of the subject's participation in the sport in the intervening time.

\section{Results}

INITIAL SCORES

Table 2 shows the mean neuropsychological test scores for the three sports on the initial assessment occasion. Using one way analysis of variance there were significant differences on eight of the 12 tests, including the three timed assessments and all in the direction suggesting that boxing performed less well than sports that acted as controls.

A correlational analysis using number of previous bouts with initial neuropsychological scores was performed to examine whether the inferior initial scores for boxing was a result of dysfunction caused by previous competition. The correlations for the 12 tests ranged from 0.299 (word recognition - errors) to -0.207 (immediate visual recall) with no correlation proving significant, although effects of boxing would have had to be large to emerge as significant against the background of premorbid variation in ability.

Further analysis of the possibility of low scores being a result of dysfunction caused by previous contests was carried out by comparing the group of 11 boxers with no history of previous contests (novice) against 16 boxers with a history of 30 or more contests (experienced). A two sample $t$ test produced $\mathrm{p}$ values ranging from $0 \cdot 11$ to $0 \cdot 88$, none of which

Table 2 Mean initial scores for each sport on the twelve neuropsychological assessments

\begin{tabular}{lcccc}
\hline & Boxing & Water polo & Rugby & Sig level $(p<0.05)$ \\
\hline Immediate visual recall & 10.9 & 12.1 & 11.6 & $\mathrm{~ns}$ \\
Visual scanning & 2.52 & 2.20 & 2.18 & 0.001 \\
Immediate word recall & 7.79 & 9.71 & 9.49 & $<0.001$ \\
Speed information processing & 199 & 232 & 225 & $<0.001$ \\
Recall design & 16.0 & 24.7 & 22.0 & $<0.001$ \\
Serial addition & 60.4 & 36.8 & 41.3 & $<0.001$ \\
Delayed visual recall & 6.99 & $8 \cdot 26$ & 7.60 & $\mathrm{~ns}$ \\
Delayed word recall & 3.38 & 5.48 & 5.09 & $<0.001$ \\
Visual recognition & 11.7 & 12.8 & 12.5 & $\mathrm{~ns}$ \\
Visual recognition (error) & 5.74 & 2.71 & 3.47 & $<0.001$ \\
Word recognition (eror) & 8.4 & 9.6 & 9.1 & $\mathrm{~ns}$ \\
Word recognition (error) & 4.04 & 2.16 & 2.77 & 0.02 \\
\hline
\end{tabular}

was significant. In comparison with the controls therefore there is no evidence that the discrepant initial scores were due to dysfunction caused by a previous history of boxing. However the sample number in each group was relatively small and a large difference would have had to exist for it to be significant.

The possibility of initial low scores being caused by boxers recovering from a previous bout was carried out by comparing the test scores of a group $(n=42)$ who had not boxed in the 28 days before assessment with a group $(\mathrm{n}=44)$ who had boxed in the 28 days before the assessment. A two sample $t$ test produced $p$ values between 0.99 to 0.081 and no significant result for any neuropsychological test.

EFFECT OF ONE BOUT

Any possible effects of boxing can be more powerfully examined by a consideration of subsequent changes in performance. Table 3 shows the mean difference scores between pre and post competition. Changes were in the direction of improvement for all sports on all tests with the exception of speed of information processing (water polo) and word recognition-error (boxing). Using one way analysis of variance the significant differences between the sports were on speed tests-serial addition $(p<0.001)$, visual scanning $(p<0.01)$ and speed of information processing $(p=$ $0.014)$. On each of these timed tests the sport of boxing showed the greatest improvement.

A $t$ test analysis of scores for boxers pre and post bout indicated significant differences at above $p<0.001$ level for 10 of the 12 tests and $p<0.01$ for a further test. Only one test (word recognition-errors) failed to show a significant difference between pre and post bout assessment for boxers.

Each bout following the first assessment was videotaped and a subsequent count of head blows received was undertaken by an experienced judge. The median frequency of head blows was in the range of 15-19 with a range from 0-54. A correlation of number of head blows with change in tests scores following the contest produced only one significant result - with a correlation of 0.494 $(p<0.0001)$ for speed of information processing which suggests more blows were associated with improvement. All other correlations proved not to be significant.

EFFECT OF CONTINUED PARTICIPATION

In taking a more longitudinal perspective, the change in test scores between first administration (pre competition) and final administration are presented in table 4. Significant changes in the direction of improvement occurred on 10 tests for boxing and water polo and 11 tests for rugby. Significant differences between sports were on serial addition $(p<0.001)$ where boxing showed greater improvement than the other sports, and delayed word recall ( $p<0.001)$, word recognition and recall design $(p<0.01)$, where rugby and water polo showed greater improvement than boxing. 
Table 3 Pre and post competition differences for each sport

\begin{tabular}{|c|c|c|c|c|}
\hline & Boxing & Water polo & Rugby & Sig level $(p<0.05)$ \\
\hline Immediate visual recall & $1 \cdot 39$ & $2 \cdot 00$ & $2 \cdot 37$ & ns \\
\hline$V^{\text {Visual scanning }{ }^{\star}}$ & $-0 \cdot 26$ & -0.07 & -0.04 & 0.003 \\
\hline Immediate word recall & 1.50 & $2 \cdot 04$ & 1.47 & ns \\
\hline Speed of information processing & $11 \cdot 5$ & $-3 \cdot 7$ & $6 \cdot 4$ & 0.014 \\
\hline Recall design & $1 \cdot 87$ & $2 \cdot 42$ & $2 \cdot 84$ & \\
\hline Serial addition* & $-8 \cdot 8$ & $-3 \cdot 5$ & $-2 \cdot 8$ & $<0.001$ \\
\hline Delayed visual recall & 3.09 & $3 \cdot 58$ & 3.53 & ns \\
\hline Delayed word recall & 1.98 & $2 \cdot 40$ & $2 \cdot 28$ & ns \\
\hline Visual recognition & $1 \cdot 31$ & 1.42 & $1 \cdot 78$ & ns \\
\hline Visual recognition ${ }^{\star}$ - errors & $-2 \cdot 11$ & -1.00 & -1.63 & ns \\
\hline Word recognition & 2.06 & $2 \cdot 77$ & $2 \cdot 28$ & ns \\
\hline Word recognition ${ }^{\star}-$ errors & 1.08 & -0.35 & -0.37 & ns \\
\hline
\end{tabular}

„Improvements on these tests have a negative $(-)$ value, indicating improvement in speed (visual scanning, serial addition), or reduction in errors (vis recog - error, word recog error).

The number of bouts between post bout assessment and follow up ranged from $1-18$ with a median number of 4 bouts. A correlation analysis between number of bouts and change in test score produced correlations ranging from 0.331 to -0.292 with no significant findings.

A $t$ test comparison between post bout (boxers) and follow up scores on the neuropsychological tests produced no significant differences on 10 tests indicating that for the most part the improvements made at post bout were maintained at follow up.

\section{Discussion}

Nine studies have reported on the neuropsychological effects of amateur boxing, yet for the most part the examinations have been confined to former boxers. Only 72 boxers from across these studies were currently active in the sport at the time of assessment. This study reports on 86 boxers active at the time of the initial pre bout assessment and thus forms a major investigation into level of cognitive functioning. Of the five studies not employing control sportsmen, three found no evidence of abnormality in neuropsychological functioning. ${ }^{2021} 23$ This has subsequently been confirmed with investigations comparing boxing with athletes from non contact sports such as track and field ${ }^{323}$ and head contact sports such as soccer ${ }^{22}{ }^{32}$ and amateur boxers in training. ${ }^{31}$ The present study essentially confirms this finding whereby in comparison with controls from rugby union and water polo, amateur boxing showed no evidence of causing neuropsychological damage either from one bout or following a series of

Table 4 Changes in neuropsychological scores at follow up for each sport

\begin{tabular}{|c|c|c|c|c|}
\hline & Boxing & Water polo & Rugby & $\begin{array}{l}\text { Between sports } \\
\text { Sig level }(p<0.05)\end{array}$ \\
\hline Immediate visual recall & $1 \cdot 29^{\star \star}$ & $-1 \cdot 69^{\star}$ & $1.97 \star \star$ & ns \\
\hline Visual scanning ${ }^{+}$ & $-0 \cdot 24^{\star \star}$ & $-0 \cdot 16^{\star}$ & $-0 \cdot 22^{\star \star}$ & ns \\
\hline Immediate word recall & $1 \cdot 11^{\star \star}$ & $1.97^{\star}$ & $2 \cdot 81 \star \star$ & ns \\
\hline Speed of information processing & $12 \cdot 4^{\star \star}$ & 4.9 & $13 \cdot 4^{\star}$ & ns \\
\hline Recall design & $1 \cdot 64^{\star}$ & $3 \cdot 00^{\star \star}$ & $4 \cdot 48^{\star \star}$ & 0.003 \\
\hline Serial addition ${ }^{+}$ & $-11 \cdot 2^{\star \star}$ & $-4 \cdot 8^{\star \star}$ & $-5 \cdot 8^{\star \star}$ & $<0.001$ \\
\hline Delayed visual recall & $2 \cdot 40^{\star \star}$ & $3 \cdot 21^{\star \star}$ & $3 \cdot 58^{\star \star}$ & ns \\
\hline Delayed word recall & $1 \cdot 35^{\star \star}$ & $3 \cdot 28^{\star \star}$ & $3 \cdot 43^{\star \star}$ & $<0.001$ \\
\hline Visual recognition & 0.02 & $1.66^{\star}$ & $1.97^{\star \star}$ & ns \\
\hline Visual recognition $^{+}-$errors & $-1 \cdot 66^{\star}$ & $-1 \cdot 38^{\star \star}$ & $-1 \cdot 93^{\star \star}$ & ns \\
\hline Word recognition & $1 \cdot 33^{\star}$ & $2 \cdot 66^{\star \star}$ & $3 \cdot 90^{\star \star}$ & 0.002 \\
\hline Word recognition ${ }^{+}-$errors & $1 \cdot 34$ & -0.48 & -0.43 & ns \\
\hline
\end{tabular}

^Improvement on these tests have a negative $(-)$ value.

Significant levels $(\star=p<0.01, \star \star=p<0.001)$ within the table refer to change between first and final administration for each sport on each test. bouts.

Subsequent follow up studies of the boxers will help to develop an understanding of whether continuing to box for a number of seasons results in any long term effects, although a recent comparison of boxers with up to 230 bouts with a group of less experienced boxers ( $0-15$ bouts) found no differences between them in neuropsychological functioning. ${ }^{32}$

Our boxers were for the most part fairly inexperienced with only 16 having 30 or more contests. Although this met our objective of studying the effects prospectively of a group of young men coming in to the sport, it raises the question of whether the results can be extrapolated to amateur boxing at a more experienced and elite level where it might be argued that the blows received are of greater strength and power, and therefore potentially more damaging. Only Kaste et al $^{21}$ have studied the elite boxer with national and European champions in their amateur sample and found no evidence for neuropsychological abnormality.

It has been argued that neuropsychological tests are a sensitive measure in detecting the early and subtle signs of brain dysfunction. ${ }^{11} 122324$ The tests employed in this investigation were for the most part standardised measures taken from the British Ability Scales and selected to examine those congnitive areas - memory and speed of functioningwhich have proved vulnerable in previous studies of professional boxers. ${ }^{20}$ The group of boxers proved to have more problems on eight of the twelve tests at the initial assessment. This appeared not to be the result of previous competition or due to boxers recovering from a bout in the month leading up to the assessment. However, because a large amount of variance would have been attributable to pre morbid level, the influence of number of bouts would need to be large for it to register as significant. If this has been indicated that boxing does not have dramatic effects there remains the possibility that it creates subtle changes in functioning. An alternative hypothesis is that if boxing variables do not appear to account for the initial lower scores, the possibility arises of a self selection for boxing for those individuals with lower levels of neuropsychological functioning. This has been proposed elsewhere ${ }^{31}$ and some evidence suggests a lower level of verbal functioning amongst amateur boxers. ${ }^{22}$ It was the case that a proportion of rugby union and water polo players were attending local university or studying for higher grades at school whilst the sample of boxers were on the whole early school leavers. The definitive analysis would require pre morbid or pre sporting estimates of intellectual functioning, the collection of which was unfortunately outside the scope of this study.

Only Heilbronner et $a l^{34}$ have previously attempted to assess the effect of one bout and were able to undertake an assessment within 45 minutes of a contest. Unfortunately they failed to have control groups. In our study 
$67 \%$ of the boxers were assessed within 24 hours of the bout and improvement on all measures of speed, compared with controls, was found. This confirms the findings of Heilbronner et al and in addition to improvements on motor speed tasks, our study suggests central processing speed improved on subsequent testing. For boxers there was possibly a greater potential range for improvement compared with the other sports because of a lower baseline level at initial assessment. It has been pointed out that neuropsychology tests emphasising speed of performance are particularly susceptible to re-test effects, ${ }^{40}$ and thus improvement might be anticipated. Further statistical analysis on expected improvement as a variable dependent upon initial level of functioning has shown that this explanation is probably unlikely. The evidence suggests that individuals scoring high on first assessment (pre competition) tended to have greater increases on scores at the second assessment (post competition) than individuals initially scoring low on the test measures. Thus the significant improvement for boxing at post competition on speed measures was greater than expected given their initial lower functioning and perhaps emphasises the view that one bout of boxing did not cause neuropsychological dysfunction.

The improvements on almost all measures following competition for all three sports and in particular significant changes on 11 of the 12 tests for boxing fits with the general finding of significant improvement on neuropsychological tests following a re-test. ${ }^{41}$ Once an individual is familiar with the test demands, they are less affected by the unique cognitive processing strategies required to complete the test. Thus improvement due to "familiarity" on retest is expected and the boxer's performance on retest was not therefore unusual or different from that which would occur in any group of individuals.

Videotaping the bout following the initial assessment enabled the punishment taken by the boxer during that bout to be assessed. An experienced boxing judge counted moderate to severe blows received to the head. Twenty two boxers received thirty or more such blows during the bout. On eleven of the tests there was no relationship between number of blows received and change in test scores following the bout providing further evidence that neuropsychological functioning appeared unaffected.

Taking a more longitudinal perspective, the improved performances on 10 of the 12 neuropsychological assessments between first assessment and follow up assessment for boxing confirms previous findings. ${ }^{33}$ The duration of follow up in the present study exceeded previous studies being on average 201 days (range 46-712). Serial addition has been shown to be particularly sensitive to the effects of head injury ${ }^{30}$ and that improvements in this test was significantly greater for boxing compared with the other two sports, further suggests a lack of deleterious cognitive effects due to boxing.
On some aspects of memory (delayed word recall, recall design, word recognition) boxers did not improve to the extent of the other sports, yet there is no evidence to suggest a deterioration occurred on these tasks, as on no test did boxers perform worse on follow up compared with initial assessment. A possible explanation for boxers not improving to the extent of other sports on these memory tests lies again in the finding that individuals of initial higher ability tended to improve performance to a greater extent than those of lower ability. Thus the likelihood is that individuals adept at a task improve more on retest than those individuals (boxers in this case) who initially show less ability on the task. Although short term memory abnormalities have been found with professional boxers ${ }^{23}$ this has not been replicated by the present study on amateur boxers or indeed by any other study on amateur boxing. ${ }^{22}$ 31-33

The number of contests between post bout and follow up assessment ranged from 1 to 18 , yet there was no relationship between the number of bouts and changes in neuropsychological functioning on the two occasions. Because no measure of the nature of the intervening bouts was undertaken it is difficult to estimate the degree of punishment boxers took in these contests. However the present analysis on number of bouts suggests no evidence of a cummulative effect with amateur boxers. This differs with results from professional boxing ${ }^{30}$ and emphasises the importance of highlighting the difference between the two forms of boxing.

Campaigns for improved safety reforms with medical attendance at ringside and examination pre and post bout, plus suspension from boxing for those who are knocked out, are now being incorported as safegurds at amateur level. ${ }^{4243}$ Given the sensitivity of neuropsychological assessments in detecting cognitive dysfunction, Ross et al $^{12}$ have advocated the employment of such tests on a regular and periodic basis. It seems apposite to argue the case for neuropsychological testing of a boxer following a knock out and before re-entry into the ring, given that the estimate of 1 to $4 \%$ of all amateur bouts end in a knock out. ${ }^{8}$ Such reforms would not lead to an enormous amount of testing but would emphasise the need for a standardised battery of neuropsychological tests which are easily administered, short in duration and sensitive to possible neuropsychological dysfunction.

Amateur boxing is conducted within relatively strict rules and guidelines and in line with a number of previous studies the evidence suggests that participation either during one bout or a series of contests does not cause subsequent neuropsychological damage.

The study was supported by Yorkshire Regional Health Authority through a locally organised research scheme and by the Leeds General Infirmary special trustees. We are grateful to Amanda Pullan for typing the manuscript, and to Dr R Baines for his statistical expertise and advice.

1 McIlvanney H. Mcllvanney on boxing: an anthology. London: Stanley Paul, 1982.

2 Patterson RH. On boxing \& liberty. Amer Med Assoc 
1986;255:2481-2.

3 Corsellis JAN. Boxing and the brain. BMF 1989;298: 105-109.

4 Cohen L. Should the sport of boxing be banned in Canada? Can Med Assoc 7 1984;130:767-8.

5 Lundberg G D. Boxing should be banned in civilized countries-Round 3. f Amer Med Assoc 1986: 255:2483-5

6 Donnelly P. On boxing: notes on the past, present and future of a sport in transition. Current Psychology. Research E Reviews 1989;7:331-46.

7 Heyman S. Ethical issues in performance enhancement approaches with amateur boxers. The Sport Psychologist 1990;4:48-54.

8 McCunney RJ. Russo PK. Brain injuries in boxers. The Physician and Sports Medicine 1984;12:53-67.

9 Morrison RG. Medical and public health aspects of boxing. $\mathcal{F}$ Amer Med Assoc 1986:255:2475-80.

10 Maliszewski $M$. Injuries in boxing: evaluations and policy decisions. The Sport Psychologist 1990;4:55-62.

11 Stiller JW, Weinberger DR. Boxing and chronic brain damage. Psychiat Clin N Amer 1985;8:339-56.

12 Ross RJ. Casson IR. Seigel O, Cole M. Boxing injuries: neurologic, radiologic \& neuropsychologic evaluation. Clinics in Sports Medicine 1987;6:41-51.

13 Martland HS. "Punch Drunk". F Amer Med Assoc 1928; 91:1103-7.

14 British Medical Association. Board of Science and Education Working Party on Boxing. Report. London: BMA, 1984.

15 Jordan BD. Boxer's encephalopathy. Neurology 1990;40: 727.

16 Johnson J. Organic psychosyndromes due to boxing. $B r f$ Psychiatry 1969;115:45-53.

17 Roberts AH. Brain damage in boxers. $A$ study of the prevalence of traumatic encephalopathy among exprofessional box-
ers. London: Pitman Medical and Scientific, 1969 .

18 Harvey PKP. Newsom Davis J. Traumatic encephalopathy in a younger boxer. Lancet 1974;19:928-9.

19 Corsellis JAN, Bruton CJ, Freeman-Browne D. The aftermath of boxing. Psychological Medicine 1973;3:270-303.

20 Ross RJ, Cole M, Thompson JS, Kim KH. Computed tomography, EEG, and neurologic evaluation. $\mathcal{f} \mathrm{Am}$ Med Assoc 1983:249:211-3.

21 Kaste $M$, Kuurne T, Vilkki J, Katevuo K, Sainio K, Meurala $\mathrm{H}$. Is chronic brain damage in boxing a hazard of the past? Lancet 1982;2:1186-8.

22 Thomassen A, Juul-Jensen P, DeFine Olivarius B, Braemer J, Christensen AL. Neurological, electroencephalographic and neuropsychological examination of cephalographic and neuropsychological examination of 53 former
60:352-62

23 Casson IR, Seigel O, Sham R, Campbell EA, Tarlau M, Didomenico A. Brain damage in modern boxers. f Amer Med Assoc 1984;251:2663-7.

24 McLatchie G, Brooks N, Galbraith S, Hutchinson JSF, Wilson L, Melville I, Teasdale E. Clinical neurological examination, neuropsychology, electroencephalography
and computed tomographic head scanning in active amateur boxers. $\mathcal{F}$ Neurol Psychiatry 1987;50:96-9.
25 Haglund Y. Bergstrand G. Does Swedish amateur boxing lead to chronic brain damage? 2. A retrospective study with cerebral computed tomography and magnetic resowith cerebral computed tomography and magnetic

26 Haglund Y, Edman G, Murelius O, Oreland L, Sachs C. Does Swedish amateur boxing lead to chronic brain damage? 1. A retrospective medical, neurological and personality trait study. Acta Neurol Scand 1990; 82:245-52

27 Haglund Y, Persson HE. Does Swedish amateur boxing lead to chronic brain damage? 3. A retrospective clinical neurophysiological study. Acta Neurol Scand 1990; 82:353-60.

28 Drew RH. Templar DI, Schuyler BA, Newell TG, Cannon WG. Neuropsychological deficits in active licensed professional boxers. F Clin Psychol 1986; 42:520-5.

29 Sironi VA, Scotti G, Ravagnati L, Franzini A, Marossero F. CT-scan and EEG findings in professional pugilists: early detection of cerebral atrophy in young boxers. $f$ Neurosurgery $S c i$ 1982;26:165-8.

30 Gronwall $D$, Wrightson $P$. Cumulative effect of concussion. Lancet 1975;2:995-7.

31 Brooks N, Kupshik G, Wilson L, Galbraith S, Ward R. A neuropsychological study of active amateur boxers. $\mathcal{F}$ Neurol Neurosurg Psychiatry 1987;50:997-1000.

32 Murelius O, Haglund Y. Does Swedish amateur boxing lead to chronic brain damage? 4 . A retrospective neuropsychological study. Acta Neur Scand 1991;83:9-13.

33 Levin HS, Lippold SC, Goldman A, Handel S, High WM, Eisenberg HM, Zelitt D. Neurobehavioural functioning and magnetic resonance imaging findings in young boxers. $\mathcal{F}$ Neurosurgery $1987 ; 67: 657-67$.

34 Heilbronner RL, Henry GK, Carson-Brewer M. Neuropsychologic test performance in amateur boxers. Amer $\mathcal{f}$ psychologic test performance in

35 Chadwick O, Rutter M, Brown G, Shaffer D, Traub M. A prospective study of children with head injuries: II. Cognitive sequelae. Psychological Medicine 1981;11: 49-61.

36 Neisser V. Decision time without reaction time: experiments in visual scanning. Amer $\mathcal{f}$ Psychol 1963; 76:376-85.

37 Thompson PJ, Trimble MR. Sodium Valproate and cognitive functioning in normal volunteers. $\mathrm{Br} f \mathrm{Clin}$ Psychol 1981;81:819-24.

38 Elliott CD, Murray DJ. The measurement of speed of problem solving and its relation to children's age and problem solving and its relation to

39 Gronwall D, Wrightson P. Delayed recovery of intellectual function after minor head injury. Lancet 1974; tual functi

40 Lezak MD. Neuropsychological assessment 2nd ed. New York: Oxford University Press, 1983.

41 Macciocchi SN. "Practice makes perfect": Retest effects in college athletes. $\mathcal{F}$ Clinical Psychology 1990;46:628-31.

42 Ludwig R. Making boxing safer: the Swedish model. f Amer Med Assoc 1986;255:2482.

43 Jordan BD. Medical and safety reforms in boxing. f National Med Assoc 1988;80:407-12. 